\title{
Nurse managers' perceptions of mentoring in the multigenerational workplace: a qualitative descriptive study
}

\author{
AUTHORS \\ TRACEY COVENTRY PhD, MNEd, BSc(Nursing), RN ${ }^{1}$ \\ ANNE-MAREE HAYS MEd, Grad Dip Ed, BA ${ }^{2}$
}

1 School of Nursing \& Midwifery, University of Notre Dame Australia, Fremantle, Western Australia, Australia

2 Edith Cowan University, Joondalup, Western Australia, Australia

\section{CORRESPONDING AUTHOR}

TRACEY COVENTRY School of Nursing \& Midwifery, University of Notre Dame Australia, 19 Mouat Street (PO Box 1225) Fremantle WA 6059, Australia. Phone: +61 89433 0934. Email: Tracey.coventry@nd.edu.au

\section{ABSTRACT}

Objective: To examine how nurse managers in metropolitan healthcare organisations in Western Australia perceive intergenerational mentoring and its place in the contemporary workforce.

Background: Mentoring in nursing has benefits for professional career success, new role transition and as a strategy to mitigate negative workplace influences.

Study design and methods: A qualitative descriptive study with 20 nurse managers from public and private health services. Face to face semi-structured interviews were held at a neutral location. The interview schedule included 10 questions which were audio-recorded and transcribed verbatim. Thematic analysis was applied to data to generate themes and present the results.

Results: Four main themes were identified: conceptualising mentoring, adding value, influences and support mechanisms, and workforce investment. The nurse managers described the positive and negative aspects of their understanding of intergenerational mentoring practice in the contemporary clinical setting.
Discussion: The nurse managers highlighted the importance of life experience in mentoring relationships and how mentoring was generationally bi-directional. As part of everyday nursing practice mentoring was evident despite clinical and organisational challenges. Clear benefits identified were the creation of a positive workforce, promotion of quality patient-centred care, and retention of staff. Mentoring has traditionally occurred face to face however, the recent coronavirus pandemic has provided a catalyst for increasing the use of online mentoring across all generations.

Conclusion: The nurse managers were willing to be involved in intergenerational mentoring in either a mentor or mentee role or both. This view of practice occurred throughout the professional work life of nurses with benefits for all generations and the continuity of organisational values.

Implications for practice: Mentoring is a practice necessary for promoting best practice in patient care and effective relationships in teams of staff. Consideration of accessibility through e-mentoring could increase involvement and take mentoring forward in the digital age. 
What is already known about the topic?

- Nursing shortages are predicted

- There are multiple generations in the nursing workplace which can contribute to issues in communication and workplace harmony

- The term mentoring is applied to numerous programs and practices in the contemporary workplace

What this paper adds:

- Current Western Australian clinical nursing managers perspective on the value of intergenerational mentoring in their workplace
- Exploration of intergenerational mentoring as a strategy for retention and succession planning in nursing

- Mentoring in action supports the promotion of quality patient-centred care and positive workplace relationships

Keywords: Mentoring; nurse managers; workplace; intergenerational; clinical support

\section{OBJECTIVE}

The contemporary healthcare system is a challenging environment for all nurses. Increasing demand and costs, inequities and complexities in resource allocation affecting performance, and quality and safety of patient outcomes are well documented issues. ${ }^{1}$ In this environment, the nurse managers (NM) as senior nurses are responsible for the 24 hour management of a ward or group of wards in a hospital. The NMs also act as the liaison between the organisation executive and the patient by taking responsibility for ward operational needs and ensuring the provision of patientcentred care. ${ }^{2}$ For NMs, the internal and external influences are connected to the rapid expansion of global health, where social, cultural and political factors have significant influence on modern healthcare practices. 3

The NMs have a unique role in setting the tone of their workplace by supporting and valuing the contribution of the team members in providing quality patient care. A dynamic and productive team is known to invest not only in their own personal and professional development, but also in that of their colleagues. ${ }^{4}$ Mentoring in nursing is generally recognised as a mutually beneficial relationship between an experienced nurse and a less experienced nurse. Through which the less experienced nurse's knowledge and skill set is materially enhanced, and their self-concept and selfefficacy are fostered. ${ }^{5}$ The purpose of mentoring is identified as professional development, engagement, enhancement and advancement. ${ }^{6}$ Mentoring programs support healthy workplaces and provide a framework to engage both new and experienced nurses in learning.7 Indeed, mentoring can impact on recruitment, retention and succession planning, ${ }^{8}$ job satisfaction, positive patient outcomes and cost savings. 4 In many workplaces, culture is a substantial concern with nurses experiencing burnout, work stress and bullying. ${ }^{9}$ Therefore, NMs who champion mentoring in the multigenerational workplace can play a key role in ameliorating these negative impacts, and support retention goals, foster positive workplace relationships, increase skill and knowledge development, and enhance patient safety. ${ }^{5}$

Mentoring is defined as lifelong professional learning for engagement, sharing of best practice, support, sustainment of employment and career progression..$^{5,10}$ In this study, the term intergenerational mentoring is used to acknowledge the valuable, differing experience and perspectives that all nurses bring to a bi-directional mentoring relationship, regardless of their age or career stage. The NMs in this study were interviewed in order to understand their perspective on current practices of mentoring in their workplaces and the value they placed on intergenerational mentoring. This knowledge could then be used to inform contemporary Western Australian (WA) healthcare organisational nursing practices, if it is found to be viewed as a beneficial workplace structure to both retain and attract staff.

\section{BACKGROUND}

A sustainable, adaptive, contemporary nursing workforce is required to meet the demands of the healthcare system. The demands include an ageing population, increasingly complex and chronic conditions, consumer expectations, and challenging financial constraints. ${ }^{11}$ Mature nurses are integral to sustaining the multigenerational workforce and contribute their unique wisdom underpinned by years of experience, knowledge and skill in the changing health environment. ${ }^{12}$ In the clinical setting, maintenance of age diversity adds value through the sharing of wisdom in the workplace and benefits nurses' overall capacity and patient outcomes at the frontline of care..$^{10} \mathrm{~A}$ study by Roche and colleagues highlighted the importance of retention of mature nurses, as the average cost of turnover to the organisation per full time equivalent in Australia was $\$ 49,255 \cdot{ }^{13}$ This figure is higher in comparison to Canada and England. Such a financial outlay for recruitment is of significant concern to organisations, and strategies such as improved workplace practices with a focus on sharing knowledge and skill, are needed for ongoing quality patient care. ${ }^{14}$ 
The benefits of effective mentorship have remained a static theme in research. The benefits cited include an apparent increasing capacity for career enhancement and advancement, ${ }^{15}$ an increase of retention in early career nurses, ${ }^{16}$ new role transitions and engagement and confidence in workplace practices. ${ }^{17}$ The literature also provides insights into efficacious models for mentoring. For instance, Cottingham and colleagues suggest formal mentoring programs are more effective than informal or adhoc sessions. ${ }^{18}$ Jakubik and colleagues highlighted mentoring as a career continuum, the time and purpose changes from the beginning of the nurses' career to retirement. 5 Such formal mentoring programs frequently aim to address nursing shortages through a focus on new graduate nurses' transition to successful practice. ${ }^{19}$ In addition, mentoring programs also address the retention of valued members of staff by channelling skilled and loyal staff towards more senior roles. ${ }^{20}$ Hungerford and colleagues suggested those who share respect, kindness and consideration - goodwill - is a feature of mentorship necessary for professional career success. ${ }^{21}$ Anecdotally, this is often the case in informal mentoring programs that rely on the generosity of nurses who give their time willingly to share their knowledge and skills to enhance practice.

Intergenerational mentoring has gained momentum over recent years as nurse retention has become a workforce priority. ${ }^{22}$ Present in the clinical environment are four generations of nurses, which can be characterised as Traditionalists, Baby Boomers, Generation X and Generation Y or Millennials. ${ }^{23}$ The variety of generations has implications for NMs' management and leadership styles, staff productivity, job satisfaction and positive patient care outcomes. ${ }^{24}$ Some intergenerational differences in the workplace are identified as the gap between worldviews, the ability to relate and the varied perceptions of clinical risk. ${ }^{25,26}$ The differences between generations can also create a general lack of tolerance to variations in personal characteristics and incorporate susceptibility to bullying and intergenerational conflict. ${ }^{27,28}$ Consequently, the impact of generational discord affects organisations through performance issues, absenteeism and increased staff turnover. ${ }^{29}$ In addition, generational arrogance in the workplace negatively influences team harmony and undermines patient-centred care strategies. ${ }^{30}$ Thus, discord between nurses at different ages and stages of their careers can contribute negatively to workplace culture and workforce retention.

Intergenerational mentoring can mitigate this discord with communication of knowledge and experience, pivotal in increasing confidence and reducing generational conflict. ${ }^{31}$ Moreover, mature nurses can be the inspiration needed when newer nurses' ability to meet daily clinical challenges is questioned impacting on retention. ${ }^{32}$ Nelsey and Brownie suggested generational harmony in the workplace improves when effective mentorship has a two-way impact on clinical practice and teamwork. ${ }^{23}$ Thereby creating empowered nurses who provide quality patient care and remain in healthcare. Thus, intergenerational mentoring is a strategy that may address some of the negative influences commonly found in the nursing workplace. ${ }^{28}$

More needs to be understood about the extent to which the contemporary Australian workforce context is supportive of, and conducive to intergenerational mentoring. The NMs were chosen as the focus of this study as their perspective was key to understanding the value placed on intergenerational mentoring in the contemporary workplace. In their leadership role, NMs have access to resources, are willing to invest in staff, 33 and are in a position to foster both formal and informal mentoring practices. 4

Despite the benefits of the mentoring relationship listed in literature, the reality is that nurses often have extra responsibilities and activities that are beyond already overwhelming workloads. ${ }^{18}$ Without organisational sponsorship, time for mentoring during workhours is often non-existent, being viewed as exceeding the requirements of the job. Also, the ever-changing environment of complexity, financial and workforce demands affect active participation in a mentoring relationship. ${ }^{25}$ Reflection on the COVID-19 pandemic, for example, reported an increased concern for newly qualified nurses and nurses returning from retirement, entering the workforce without appropriate support. ${ }^{34}$ The point of need in these challenging times may see a reimagining of mentoring formats. As a result, mentoring relationships may increasingly take the form of e-mentoring, which allows people to be involved in and out of hours and despite distance or multi-campus organisations. E-mentoring platforms - software used to host a mentoring application or service-support not only one-on-one relationships but can allow for small group mentoring to take place increasing accessibility. 35

The Western Australian Chief Nursing and Midwifery Office articulated the nursing and midwifery strategic direction for 2018-2021, ${ }^{6 \text { (para4) }}$ as inclusive of workforce excellence by 'building leadership capacity and capability to optimise performance, outcomes and the development of cultures that prioritise compassionate care and patient safety'. In addition, the demand for nurses exceeding supply in the near future will present financial challenges in recruitment and retention, thus strategies that reduce voluntary turnover are valuable to an organisation. ${ }^{12}$ Therefore, intergenerational mentoring may be a key strategy to positively affect workforce retention, reduce the impact of a negative clinical environment, and achieve a cohesive culture of quality patient care. ${ }^{15}$ The purpose of this study was to describe NMs perceptions of the factors that enabled or constrained intergenerational mentoring in their workplace. 


\section{STUDY DESIGN AND METHODS}

A single stage qualitative descriptive research design using semi-structured interviews was employed to explore mentoring in the nursing context from the NMs perspective. Qualitative research is favoured by health researchers interested in social areas that are evolving and changing, such as the multigenerational health care workplace. ${ }^{37}$ Features of this design included an interpretation of naturalistic inquiry with the sample of participants chosen as being able to describe the 'who, what and where of events or experiences'.$^{8}$ The NMs experiences and perceptions were summarised and presented systematically to provide a comprehensive account of mentoring engagement in intergenerational learning relationships in the clinical environment. This study adhered to the National Statement on Ethical Conduct in Human Research, ${ }^{39}$ demonstrating the core principles of respect and ethical conduct. This guided the informed, voluntary consent process and the protection of participants through the use of codes to minimise identification potential. University ethical clearance was granted for the study (NDo17172F/ECU20173).

\section{SAMPLE}

The target population were NMs from metropolitan public and private hospitals in Western Australia (WA). To be included in the study the NMs were required to represent and provide support for nursing staff at ward level to deliver quality and safe nursing care and be responsible for ward management functions. NMs were excluded if they were primarily administrative or executive and did not provide support for nursing staff at ward level. The purposive sample was anticipated to be small enough to achieve data saturation which occurred when no new data emerged from individual participants. ${ }^{40}$ The NMs were recruited through health service networking contacts with each potential NM receiving an email invitation that contained the study information and researcher contact details.

\section{DATA COLLECTION AND ANALYSIS}

Data collection continued until a total of 20 NMs from both public and private WA hospitals were interviewed, at which point saturation was reached. ${ }^{41}$ The interview schedule comprised of 10 mentoring questions derived from a preliminary literature review with eight designed with a closed/open ended question sequence and two open ended questions (see Table 1 ). The use of the initial closed question allowed the participants to respond with a positive or negative position, from which supplemental prompts were used to ensure the productive collection of data. ${ }^{22}$ Spontaneous follow up questions were also used to encourage the participants to add further information. 43 Face validity of the questions occurred with two educational researchers and a NM colleague with changes made to ensure clarity of wording and flow from topic to topic..$^{41} \mathrm{~A}$ pilot test of the interview was also considered necessary to aid timing and make further adjustments to the questions. ${ }^{42}$ Interviews were no longer than 6o minutes in duration, were audiorecorded on a digital recorder and held at a neutral location outside the NMs' workplace.

Participation was voluntary, NMs were provided with a comprehensive information sheet and informed written consent was obtained. Pseudonyms were used from the time of recording and throughout data analysis and reporting for anonymity. Scientific rigour was considered through the lens of trustworthiness, a key dimension in evaluating a qualitative study. ${ }^{41}$ The following strategies were demonstrated in this study: researchers independently reviewed the transcripts identifying initial themes prior to collaborative discussion to achieve consensus, and a record of the data coding, management and reporting provided evidence of accuracy of findings.

\section{TABLE 1: INTERVIEW SCHEDULE}

\begin{tabular}{|c|c|c|}
\hline & Question & Prompts \\
\hline 1 & $\begin{array}{l}\text { How would you define } \\
\text { intergenerational } \\
\text { mentoring? }\end{array}$ & $\begin{array}{l}\text { Is it a commonly used term in } \\
\text { your workplace? } \\
\text { What terms are used to } \\
\text { describe intergenerational } \\
\text { mentoring in your workplace? }\end{array}$ \\
\hline 2 & $\begin{array}{l}\text { Do you personally believe } \\
\text { that intergenerational } \\
\text { mentoring is important? }\end{array}$ & Why/why not? \\
\hline 3 & $\begin{array}{l}\text { Do you believe } \\
\text { intergenerational mentoring } \\
\text { is viewed as important by } \\
\text { your employer? }\end{array}$ & $\begin{array}{l}\text { Why/why not? } \\
\text { What has led you to believe } \\
\text { this? } \\
\text { Any specific strategies that are } \\
\text { endorsed? }\end{array}$ \\
\hline 4 & $\begin{array}{l}\text { Are there barriers to } \\
\text { intergenerational mentoring } \\
\text { in your workplace? }\end{array}$ & $\begin{array}{l}\text { If yes, please provide examples. } \\
\text { If no, why do you think this is } \\
\text { the case? }\end{array}$ \\
\hline 5 & $\begin{array}{l}\text { What do you see as the } \\
\text { benefits of mentoring for an } \\
\text { organisation? }\end{array}$ & $\begin{array}{l}\text { A hospital? } \\
\text { Staff? } \\
\text { Patients? }\end{array}$ \\
\hline 6 & $\begin{array}{l}\text { In your current role as } \\
\text { an NM, do you actively } \\
\text { support intergenerational } \\
\text { mentoring? }\end{array}$ & $\begin{array}{l}\text { If yes, how do you do this? } \\
\text { Please provide explicit } \\
\text { examples. } \\
\text { Do you feel that your efforts are } \\
\text { successful? } \\
\text { If no, why not? }\end{array}$ \\
\hline 7 & $\begin{array}{l}\text { Were you mentored as an } \\
\text { early career nurse? }\end{array}$ & $\begin{array}{l}\text { If yes or no, do you feel this } \\
\text { influenced your confidence and } \\
\text { competence as a nurse? } \\
\text { If yes or no, has this influenced } \\
\text { your attitude toward the value } \\
\text { of intergenerational mentoring? }\end{array}$ \\
\hline 8 & $\begin{array}{l}\text { Did you have training in } \\
\text { intergenerational mentoring } \\
\text { as a pre-registration nurse? }\end{array}$ & Is this adequate? \\
\hline 9 & $\begin{array}{l}\text { Does your workforce provide } \\
\text { support for both mentors } \\
\text { and mentees? }\end{array}$ & $\begin{array}{l}\text { Is this adequate? } \\
\text { Are there gaps that need to be } \\
\text { addressed? }\end{array}$ \\
\hline 10 & $\begin{array}{l}\text { Does intergenerational } \\
\text { mentoring have an influence } \\
\text { on attrition in your } \\
\text { workplace? }\end{array}$ & $\begin{array}{l}\text { If yes, why? } \\
\text { If no, why not? }\end{array}$ \\
\hline
\end{tabular}


The interviews were transcribed verbatim, the written text read and reread to illuminate language and cultural nuances. ${ }^{44}$ The data were entered into the NVivo 11 tool to support systematic text-based data organisation, management and analysis. ${ }^{45} \mathrm{~A}$ methodical process of categorising the data was used to identify the categories and themes from the transcribed interviews. Braun and Clarke's thematic analysis framework provided a clear step by step process to focus and present data in an accessible form. ${ }^{46}$ The six phases of thematic analysis included familiarity with the transcribed data; systematic coding of interesting features of intergenerational mentoring; searching for potential themes, reviewing the potential themes against the original data, naming the themes, and producing the narrative.$^{46}$ The resulting themes highlighted the NMs perceptions of intergenerational mentoring and its place in the contemporary workforce.

\section{RESULTS}

The participants characteristics, of which the majority are female, aged in their 40 and with more than 20 years of experience in nursing, are detailed in Table 2.

\section{TABLE 2: NURSE MANAGER CHARACTERISTICS}

\begin{tabular}{|c|c|c|}
\hline Characteristic & in sample $(n=20)$ & in sample (\%) \\
\hline \multicolumn{3}{|l|}{ Gender } \\
\hline Female & 16 & 80 \\
\hline Male & 4 & 20 \\
\hline Other & 0 & 0 \\
\hline \multicolumn{3}{|l|}{ Age Group } \\
\hline $20-29$ & 1 & 5 \\
\hline $30-39$ & 3 & 15 \\
\hline $40-49$ & 11 & 55 \\
\hline $50-59$ & 3 & 15 \\
\hline $60-69$ & 2 & 10 \\
\hline \multicolumn{3}{|c|}{ Country of Origin } \\
\hline Australia & 10 & 50 \\
\hline United Kingdom & 7 & 35 \\
\hline Other & 3 & 15 \\
\hline \multicolumn{3}{|l|}{ Years in Nursing } \\
\hline $0-9$ & 1 & 5 \\
\hline $10-19$ & 6 & 30 \\
\hline $20-29$ & 6 & 30 \\
\hline $30-39$ & 4 & 20 \\
\hline $40-49$ & 3 & 15 \\
\hline \multicolumn{3}{|c|}{ Years in Management } \\
\hline $0-9$ & 10 & 50 \\
\hline $10-19$ & 9 & 45 \\
\hline $20-29$ & 1 & 5 \\
\hline
\end{tabular}

The focus of this study was on the intergenerational transmission of knowledge and skill. However, in practice the NMs considered the term 'mentoring' as a broader concept consisting of a relationship between two nurses, with either nurse the beneficiary of the other's skill set and experiences or both benefiting from the relationship. The analysis identified four main themes: conceptualising mentoring, adding value, influences and support mechanisms, and workforce investment. These four themes are explored below, with the inclusion utilising transcribed participant commentary. This shows the participants' understanding of the positive and negative aspects of intergenerational mentoring in the contemporary clinical setting.

\section{CONCEPTUALISING MENTORING}

The first theme identified the variance in the understanding and application of the term intergenerational mentoring. Many of the participants were unaware of this term, though clear on what mentoring meant to them; "Mentoring is mentoring, so it's passing on your skills, knowledge, attitudes and behaviours to other members of staff'. Some participants though, were able to articulate their understanding of mentoring as transmission of learning across generations: "Like your Baby Boomers ... Generation X's and the Millennials, or the Zs" and "based on age and the different age groups of the mentors we have on the ward, and not only from an age perspective, but also from experience".

Mentoring was more commonly described by participants as a strategy where age was immaterial and life and nursing experience important: "There are a lot of mature-age students coming through and so it's definitely a case of age is irrelevant ... they can have a whole career before coming into nursing". Participants commented on the mutually shared generational middle ground where junior nurses brought new knowledge, skills and technology to the workplace and more senior nurses shared their expertise: "Because everyone's learning from each other; the older nurses have more to bring sometimes to the stage that the younger ones can actually learn from, and vice versa ... so they kind of balance each other out". Thus, active mentoring was seen as generationally bidirectional, "Mentoring up or mentoring down ... there's lots of nurses who are older than me that I would mentor and vice versa". NMs saw mentors who could offer something more, "A mentor that I could associate better with, that was a bit younger, a bit more contemporary".

\section{ADDING VALUE}

The second identified theme was around the positive value that mentoring added to the contemporary workplace. Mentoring was described as a part of everyday nursing activity, rather than a formally defined additional role; "It is around nurturing ... and helping that person grow in what they're doing, whether it's clinical, or whether it's leadership, or some other element of nursing". In discussing 
intergenerational mentoring specifically, the generations were considered important to mentoring as "More newer to nursing are more theoretical ... the older generation, maybe a bit more practical”. Mentoring provided the vehicle to integrate the generations through sharing knowledge, practical skills and expertise. The NMs encouraged the older generation of nurses in the workplace to impart their unique perspective of their speciality area, especially in relation to practical experience; "How to read a scenario, situational awareness” which “Isn't anywhere in a textbook, they're the things that come with experience". NMs mentioned the deficits produced from a lack of practical experience during the current nurse training; “There's a lot now that isn't taught in universities that our older nurses can teach us ... especially bedside skills are lacking because there is such a reduction in the time that students have on practicum". Another NM highlighted that time spent talking to patients, once regarded as basic nursing care, was now considered by the older generation of nurses as a skill to pass on; "I still think that we need to be able to demonstrate and instil in the next generations that that's a huge part of our nursing... I think often gets missed". Regardless of the generational differences the importance of mentoring was recognised as a way to value multigenerational staff;

"If you want to get the best out of your staff, you need to be able to interact with them ... in a way that's meaningful to them ... by understanding the things that different generations find important ... so that they feel supported, they feel like they're able to contribute ... they feel valued".

Challenges in the clinical environment such as higher patient acuity, quick patient flow and added technological requirements influenced contemporary nursing care. NM participants explained that nurses were often "far too busy to look after other nurses" and "so focused on tasks, doing things and getting things done" that they avoided using these times as learning opportunities.

The NMs valued the knowledge junior nurses brought; "Younger people can also mentor people who have been in nursing for much longer because they're actually current; up to date with research and up to date with current changes". The provision of technological expertise was particularly noted in the advantages of intergenerational mentoring, "The young ones can actually teach them [the older nurses] about new technology".

\section{INFLUENCES AND SUPPORT MECHANISMS}

The third identified theme highlighted the place of mentoring in shaping the experiences of those in the profession. Mentoring, across the generations through role modelling and leadership provided an opportunity to visibly incorporate nursing skills and attitudes. Participants suggested mentoring in their workplace was worthwhile to "foster respect", provide "pastoral care", show "appreciation" and to prevent "burnout and compassion fatigue ... for sustainability of nurses". Smaller and salient details of mentoring can make a difference to the individual nurse of any generation; "Show you the ropes, to allow you to have that sense of belongingness, and show that you do fit in in the environment that you're in, making sure that your name is on the board, somebody to look out for you". Professionalism is also affected by the culture of the workplace and the positive impact mentoring can have, "It's about the supportive workplace, it's about a culture that supports your peers". However, participants indicated that mentoring across generations was not always successful. NMs commented that this may be in relation to apathy, "I can try and instil something into them, and they nod their head but they walk away, and it doesn't get done” or a difference in intergenerational priorities, "The slightly older nurses have a better understanding and requirement of what the job requires, e.g. rosters, whereas, generally, the young people, want weekends off because they want to go to parties".

Support for any type of mentoring in the participants' workplace was variable. Many participants suggested budget constraints as limiting the opportunities for mentorship, "No [support] - because of the financial implications". Lack of time was indicated as an additional barrier, "I just think people are too busy and it just kind of maybe got too hard". Formal opportunities for mentoring training were less available and more directed at staff looking after new graduates; "We have ... a four-hour education session for our mentors who are taking on our grads". Informal mentoring was more widely discussed with many suggesting mentoring was a personal choice rather than an organisational imperative; "You're kind of sort of left to find your feet ...and find your own sort of mentors".

\section{WORKFORCE INVESTMENT}

The final identified theme focused on the importance of creating a positive workforce, through intergenerational mentoring which integrated the culture and vision of the hospital and provided consistency and continuity, "You actually teach them your culture and the way we want people valued, respected, the way we work as a team". Mentoring as a concept, was highlighted as an influence in the provision of the desired quality patient-centred care;

Being part of quality and improvement of the nursing care ... and patient satisfaction and your satisfaction - you work in a job where you find people are not there to gun you, but actually to work with you and help you grow.

Improving intergenerational team dynamics and cohesion was a goal for participants. Mentoring was recognised as a way to achieve this; "Any time you can unite a team through mentoring and give people the opportunity to have someone to debrief with and self-reflect with is 
always a good thing". One consequence of a dynamic intergenerational team was patient safety and quality of care, "You have a safer team, because they are communicating, if they're unsure about anything, and with the mentoring ... if everybody in the room knows what they're doing, then you don't have mistakes". In addition, mentoring across generations targeted nurses working in challenging and stressful situations which led to positive outcomes; "They act as a mentor ... in terms of how to cope with things, coping strategies, stress relief, taking time out”. Therefore, mentorship is an investment in all ages of nurses and leads to retention and reduced turnover in the organisation; "If people feel welcome, they feel supported, they want to stay here, it's a happy environment for them, they feel safe and happy coming to work ... they feel like part of the team".

Time pressures during work time were noted as impacting on mentoring and affecting the investment in staff. Pressures included "clinical urgency", increased workloads "just too exhaustive", administration "it's a very, very significant thing that we do" and time management "we are a very busy ward". Despite these constraints, participants expressed how mentorship of the newly qualified graduate nurses by experienced nurses with knowledge and skill was an investment in the future. Graduates who have been mentored provided a useful recruitment pool of available, well-trained and flexible staff;

Most of the new employees I hire, I always look, first and foremost, at the graduates who have just finished ... because we've put so much work and effort into them, teaching them new skills, but also getting to know the people, the system and the staff.

\section{DISCUSSION}

This study adds to the contemporary picture of mentoring in a multigenerational healthcare workforce. The NMs observed intergenerational mentoring as an important practice and a critical approach to investing in nurses to meet the organisational goals of quality patient-centred care. The NMs, who despite a lack of time and funding from their employer-which limited formal mentoring-still prioritised mentoring as a valuable workplace practice. They explained that nurses engaged in the adhoc practice of mentoring because they were personally invested in the quality and safety of their patients' care. From the data, it was clear that effective mentoring was not about age, but the core beliefs about the value of mentoring in the workplace, shown by the willingness to share knowledge and skills and influence attitudes. In the clinical setting, with up to four generations of nurses working together, there are likely to be frequent misunderstandings that affect job performance. 47 Thus, intergenerational mentoring provided for consistency and continuity around organisational values and ethos and how this is demonstrated in patient care and teamwork in the workplace..$^{8}$ Therefore, allowing nurses to have 'buy-in' around organisational direction will also lead to an increase in long term retention. ${ }^{23}$

Competing priorities for mentors are frequently cited in literature. ${ }^{18,25,49}$ Negative aspects highlighted by the NMs centred around the paucity of time related to increased clinical workloads and underlined the focus on completing tasks over mentorship in any form. Mentoring is seen as an additional activity. Despite the positive outcomes reported, mentoring was relegated to outside work hours for those who were committed to the beneficial aspects of the mentor/mentee relationship. Regardless of the needs of the multigenerational workplace and the mitigating benefits of mentoring, the lack of support remains problematic. 49

Frequently discussed as an antidote to the common 'sink or swim' experience for many new nurses, ${ }^{50}$ mentoring is also a way of relating that builds bridges between new and experienced colleagues of all ages. Although, not all new nurses are Millennials, this generation of nurses has been identified as less attached to traditional practices. Highlighted by Price and colleagues, ${ }^{32}$ specific investment is required for the Millennial nurses who show a greater interest in a work-life balance that favours social interaction. However, the social media savvy and technological confident Millennial cohort, do contribute to the workplace by actively reverse mentoring when sharing their technological practices and recently gained evidence-based knowledge..$^{51}$ The use of e-mentoring is also better suited to the real time, spontaneous needs of this generation, and their mobile devices. Practical experience of the online communication occurring through video conferencing during the COVID-19 pandemic, may have provided the impetus for change in the generations of nurses who have held onto the traditional face to face forms of mentoring. The rapidly acquired skills and confidence in conducting gatherings, meetings, and presentations remotely in the online space, has been a positive catalyst for advancing mentoring practice beyond the workplace..$^{2}$

The results of this study show mentoring is viewed by the NMs as a meaningful practice. Two clear benefits were promotion of best practice patient care and positive relationships among teams of staff. Mentoring is viewed as a career enhancing practice, as described by Jakubik and colleagues, 5 as 'horizontally within or across a role and vertically into more advanced roles'.5(p.150) Many NMs would have welcomed a more formal focus on intergenerational mentoring from their organisations. Thus, NMs or nursing management could collaborate with their organisations to formally adopt mentoring programs which will have a positive impact on nursing socialisation, retention, and patient quality of care. Since nursing as a profession embodies the art of caring and is relational in nature, the formal and supported practice of intergenerational mentoring in the clinical setting would effectively allow for a 
greater shaping of the nursing profession moving forward. 53 While, intergenerational mentoring may continue in its current state; however, with technological advances and freely available social video communications, and in view of financial challenges to current staffing and organisational structures, e-mentoring may be more fully utilised in the future.

\section{STUDY LIMITATIONS}

In using a qualitative approach, this study had a limited sample of participants from one metropolitan area in one state of Australia. While being able to capture and reveal the perceptions of NMs in the context of their leadership and management role responsibility, the study may not be transferable more broadly across Australia or internationally. The NMs were enthusiastic in their responses and provided detail in stories and experiences that highlighted their understanding of nurses engaging in intergenerational mentoring in their area. However, the NMs self-report can also be considered limited by issues of bias and recollection. With the focus of the study only on the NMs, the inclusion of the varied generations of nurses themselves in the NMs clinical settings would have provided a more complete picture of the reality of intergenerational mentoring in the study context.

\section{CONCLUSION}

This qualitative descriptive study has provided an understanding of how NMs perceive intergenerational mentoring and its place in the contemporary workforce. The findings clearly demonstrate a willingness by the participants to be involved in mentoring in either a mentor or mentee role or both, with a view that it is a practice which happens throughout the professional work life of nurses. Intergenerational mentoring, both in face to face and e-mentoring mode has positive benefits for all ages and career stages of the individual nurse and for the professional nursing workforce in the clinical setting.

\section{IMPLICATIONS FOR PRACTICE}

The results of this study may indicate that mentoring is a practice that could be formally adopted by organisations as a possible way of promoting best practice in patient care, establishing effective relationships amongst teams of staff and thus increasing retention. Further research on mentoring practices with nurses involved in workplace mentoring programs will provide a more complete picture of the possible benefits to both employers and employees. Given the impact that the COVID-19 pandemic has had on the workplace and nurses in particular, further research on the e-mentoring would be timely. While, mentoring may continue in its current state, it is thought that with the advent of further technological advances and changes to current staffing and organisational structures that platforms which allow for e-mentoring may be a worthy adjunct to face to face mentoring practices.

Acknowledgement: We would like to thank the Western Australian Nurses Memorial Charitable Trust for their financial support. We are also grateful to the 20 Nurse Managers for their voluntary participation in this study.

Conflict of Interest Statement: There is no conflict of interest for either of the authors.

Funding: This study was supported by a Western Australian Nurses Memorial Charitable Trust Grant.

\section{REFERENCES}

1. Dixit SK, Sambasivan M. A review of the Australian healthcare system: a policy perspective. SAGE Open Med. 2018. Available from: https://doi.org/10.1177/2050312118769211

2. Goodyear C, Goodyear M. Career development for nurse managers. Nurs Manage. 2018; (49)3: 49-53. Available from: https://doi.org/10.1097/01.NUMA.0000530429.91645.e2

3. Mittelman M, Hanaway P. Globalization of healthcare. Glob Adv Health Med. 2012; 1(2): 5-7. Available from: https://doi.org/10.7453/gahmj.2012.1.2.001

4. Goodyear C, Goodyear, M. Supporting successful mentoring. Nurs Manage. 2018; 49(4): 49-53. Available from: https://doi.org/10.1097/01.NUMA.0000531173.00718.06

5. Jakubik LD, Weese MM, Eliades AB, Huth JJ. Mentoring in the career continuum of a nurse: clarifying purpose and timing. Pediatr Nurs. 2017; 43(3): 149-52. [Cited 2020 Apr 25] Available from: https://www.thefreelibrary.com/ Mentoring+in+the+career+continuum+ of +a+nurse\% 3A+Clarifying+purpose+and...-a0502001270

6. Tourigny L, Pulich M. A critical examination of formal and informal mentoring among nurses. Health Care Manage. 2005; 24(1): 68-76. Available from: https://doi.org/10.1097/00126450-200501000-00011

7. Chong JY, Ching AH, Renganathan Y, Lim WQ, Toh YP, Mason S, et al. Enhancing mentoring experiences through e-mentoring: a systematic scoping review of e-mentoring programs between 2000 and 2017. Adv Health Sci Edu Theory Pract. 2019; 25(1): 195-226. Available from: https://doi.org/10.1007/s10459-01909883-8

8. Saletnik L. The Importance of mentoring. AORN J. 2018; 108(4) 354-6. Available from: https://doi.org/10.1002/aorn.12386

9. Nolte AGW, Downing C, Temane A, Hastings-Tolsma M. Compassion fatigue in nurses: a metasynthesis. J Clin Nurs. 2017; 26(23-24): 4364-78. Available from: https://doi.org/10.1111/jocn.13766

10. Hale RL, Phillips CA. Mentoring up: A grounded theory of nurse-to-nurse mentoring. J Clin Nurs. 2019; 28(1-2): 159-172 Available from: https://doi.org/10.1111/jocn.14636

11. Health Workforce Australia. Australia's future health workforce - nurses overview report. 2014. [Cited 2020 Apr 25] Available from: http://www.health.gov.au/internet/main/publishing.nsf/ Content/australias-future-health-workforce-nurses 
12. Health Workforce Australia. Nursing workforce sustainability; improving nurse retention and productivity. 2014. [Cited 2020 Apr 25] Available from: http://www.health.gov.au/internet/ main/publishing.nsf/Content/nursing-workforce-sustainabilityimproving-nurse-retention-and-productivity

13. Roche MA, Duffield CM, Homer C, Buchan J, Dimitrelis S. The rate and cost of nurse turnover in Australia. Collegian. 2015; 22(4): 353-8. Available from: https://doi.org/10.1016/j. colegn.2014.05.002

14. Uthaman T, Chua TL, Ang SY. Older nurses: A literature review on challenges, factors in early retirement and workforce retention. 2016; 25: 50-55. SAGE Publications. Available from: https://doi.org/10.1177/2010105815610138

15. Lin J, Chew YR, Toh YP, Radha Krishna LK. Mentoring in nursing: an integrative review of commentaries, editorials, and perspectives papers. Nurs Educ. 2017; 43(1); E1-E5. Available from: https://doi.org/10.1097/NNE.0000000000000389

16. Brook J, Aitken L, Webb R, MacLaren J, Salmon D. Characteristics of successful interventions to reduce turnover and increase retention of early career nurses: a systematic review. Int J Nurs Stud. 2019; 91: 47-59. Available from: https://doi.org/10.1016/j.ijnurstu.2018.11.003

17. Lipscomb R, An S. Mentoring 101: Building a mentoring relationship. J Acad Nutr Diet. 2013; 113(5): S29-S31. Available from: https://doi.org/10.1016/j.jand.2013.02.010

18. Cottingham S. DiBartolo MC, Battistoni S, Brown T. Partners in nursing: a mentoring initiative to enhance nurse retention. Nurs Educ Perspect. 2011; 32(4): 250-5. Available from: https://doi.org/10.5480/1536-5026-32.4.250

19. Rush KL, Adamack M, Gordon J, Lilly M, Janke R. Best practices of formal new graduate nurse transition programs: an integrative review. Int J Nurs Stud. 2013; 50(3): 345-56. Available from: https://doi.org/10. 1016/j.ijnurstu.2012.06.009

20. Australian College of Nursing. Nurse leadership. 2015. [Cited 2020 Apr 25] Available from: https://www.acn.edu.au/wpcontent/uploads/2017/10/acn nurse leadership white paper reprint 2017 web.pdf

21. Hungerford C, Sayers J, Cleary M. Facilitating goodwill in workplace relationships: the benefits and challenges. Issues Ment Health Nurs. 2016; 37(7): 530-2. Available from: https://doi.org/10.1080/01612840.2016.1187503

22. Clipper $B$. The nurse manager's guide to an intergenerational workforce. Sigma Theta Tau International, Indianapolis. 2013.

23. Nelsey L, Brownie S. Effective leadership, teamwork and mentoring - Essential elements in promoting generational cohesion in the nursing workforce and retaining nurses. Collegian. 2012; 19(4): 197-202. Available from: https://doi.org/10.1016/j.colegn.2012.03.002

24. Mokoka KE. Managing a multigenerational nursing workforce to strengthen staff retention. Prof Nurs Today. 2015; 19(4): 42-45 [Cited 2020 Apr 25] Available from: http://www.pntonline. co.za/index.php/PNT/article/view/797

25. Foley VC, Myrick F. Yonge O. A phenomenological perspective on preceptorship in the intergenerational context. Int J Nurs Educ Scholarsh. 2012; 9: 3-9. Available from: https://doi.org/10.1515/1548-923X.2452

26. Wieck KL, Dols J, Landrum P. Retention priorities for the intergenerational nurse workforce. Nurs Forum. 2010; 45(1): 7-17. Available from: https://doi.org/10..1111/j.1744$\underline{6198.2009 .00159 . x}$
27. Frederick D. Bullying, mentoring, and patient care. AORN Journal. 2014; 99(5): 587-593. Available from: https://doi.org/10.1016/i.aorn.2013.10.023

28. Anderson LB, Morgan M. An examination of nurses' intergenerational communicative experiences in the workplace: do nurses eat their young? Commun Q. 2017; 65(4): 377-401. Available from: https://doi.org/10.1080/014633 73.2016.1259175

29. Cottingham MD, Dill JS. Intergenerational dynamics among women and men in nursing. In Choroszewicz M, Adams T, editors. Gender, age and inequality in the professions: Exploring the disordering, disruptive and chaotic properties of communication. New York: Routledge; 2019.

30. Cleary M, Walter G, Sayers J, Lopez V, Hungerford C. (2015), Arrogance in the workplace: Implications for mental health nurses. Issues Ment Health Nurs. 2015; 36(4): 266-71. Available from: https://doi.org/10.3109/01612840.2014.955934

31. Price $S$, Reichert,C. The importance of continuing professional development to career satisfaction and patient care: meeting the needs of novice to mid- to late-career nurses throughout their career span. Admin Sci. 2017; 7(2): 17. Available from: https://doi.org/10.3390/admsci7020017

32. Price SL, McGillis Hall L, Murphy GT, Pierce, B. Evolving career choice narratives of new graduate nurses. Nurse Educ Pract. 2018; 28: 86-91. Available from: https://doi.org/10.1016/j. nepr.2017.10.007

33. Pishgooie AH, Atashzadeh-Shoorideh F, Falcó-Pegueroles A, Lotfi Z. Correlation between nursing managers' leadership styles and nurses' job stress and anticipated turnover. J Nurs Manage. 2019; 27(3): 527-34. Available from: https://doi.org/10.1111/jonm.12707

34. Jackson D, Bradbury-Jones C, Baptiste D, Gelling L, Morin $K$, Neville $S$, et al. Life in the pandemic: some reflections on nursing in the context of COVID-19. J Clin Nurs. 2020; 29(1314), 2041-3. Available from: https://doi.org/10.1111/jocn.15257

35. Rowland KN. E-mentoring: An innovative twist to traditional mentoring. J Technol Manage Innov. 2012; 7(1): 228237. Available from: https://doi.org/10.4067/s0718$\underline{27242012000100015}$

36. The Western Australian Chief Nursing and Midwifery Office. WA Health Nursing and Midwifery Strategic Priorities 2018 2021. Government of Western Australia. Department of Health. [Cited 2020 Apr 25] Available from: https://ww2.health.wa.gov. au/Articles/N R/Nursing-and-Midwifery-Office

37. Creswell JW, Poth $\mathrm{CN}$. Qualitative inquiry and research design: Choosing among five approaches. 4th ed. Los Angeles: SAGE; 2018.

38. Sandelowski M. Combining qualitative and quantitative sampling, data collection, and analysis techniques in mixed method studies. Res Nurs Health. 2000; 23(3): 246-55. [Cited 2020 Apr 25] Available from: http://www.ncbi.nlm.nih. gov/pubmed/10871540

39. National Health and Medical Research Council. National statement on ethical conduct in human research. National Health and Medical Research Council, the Australian Research Council and Universities, Commonwealth of Australia. 2018.

40. Saunders B, Sim J, Kingstone T, Baker S, Waterfield J, Bartlam $B$, et al. Saturation in qualitative research: exploring its conceptualization and operationalization. Qual Quant. 2018; 52(4): 1893-907. Available from: https://doi.org/10.1007/ s11135-017-0574-8 
41. Polit DF, Beck CT. Essentials of nursing research: Appraising evidence for nursing practice. 9th ed. Philadelphia: Wolters Kluwer Health; 2018.

42. DeJonckheere M, Vaughn LM. Semistructured interviewing in primary care research: a balance of relationship and rigour. Fam Med and Community Health. 2019; 7(2): e000057. Available from: https://doi.org/10.1136/fmch-2018-000057

43. Bolderston A. Conducting a research interview. J Med Imaging and Radiat Sci. 2012; 43: 66-76 Available from: https://www.jmirs.org/article/S1939-8654(11)00132-9/pdf

44. Nascimento LDS, Steinbruch FK. "The interviews were transcribed", but how? reflections on management research. RAUSP Manag J. 2019; 54(4): 413-29. Available from: https://doi.org/10.1108/RAUSP-05-2019-0092

45. NVIVO qualitative data analysis software. QSR International Pty Ltd. Version 11, 2015.

46. Braun V, Clarke V. Using thematic analysis in psychology. Qual Res Psychol. 2006; 3(2): 77-101. Available from: https://doi.org/10.1191/1478088706qp063oa

47. King SP, Bryant FB. The workplace intergenerational climate scale (WICS): a self-report instrument measuring ageism in the workplace. J Organ Behav. 2017; 38(1): 124-51. Available from: https://doi.org/10.1002/job.2118

48. Hendricks JM, Cope VC. Generational diversity: what nurse managers need to know. J Adv Nurs. 2013; 69(3): 717-25. Available from: https://doi.org/10.1111/j.1365-2648.2012.06079

49. Bailey-McHale J, Hart D. Mastering Mentorship: A Practical Guide for Mentors of Nursing, Health and Social Care Students. London: SAGE Publications; 2013.

50. Huybrecht S, Loeckx W, Quaeyhaegens Y, De Tobel D, Mistiaen W. Mentoring in nursing education: perceived characteristics of mentors and the consequences of mentorship. Nurse Educ Today. 2011; 31(3): 274-8. Available from: https://doi.org/10.1016/j.nedt.2010.10.022

51. Foster S. Forward thinking with reverse mentoring. Br J Nurs. 2019; 28(8): 539. Available from: https://doi.org/10.12968/ bjon.2019.28.8.539

52. Gotian R. Mentoring during the COVID-19 pandemic, Nature. 2020; 3:(April 3) Available from: https://doi.org/10.1038/ d41586-020-01028-x

53. Reinbeck DM, Fitzsimons V. Bridging nursing's digital generation gap. Nurs Manage. 2014; 45(4): 12-4. Available from: https://doi.org/10.1097/01.NUMA.0000444879.08311.02 